\title{
DINAMIKA USAHA PENGGILINGAN PADI KECIL DI MASA PANDEMI COVID-19 : STUDI KASUS KECAMATAN PURBARATU, KOTA TASIKMALAYA
}

\author{
THE DYNAMICS OF THE SMALL RICE MILLING BUSINESS \\ DURING THE COVID-19 PANDEMIC: CASE STUDY IN PURBARATU, \\ TASIKMALAYA CITY
}

\author{
Nisrina Guzmarani**1, Mahra Arari Heryanto ${ }^{2}$, Elly Rasmikayati \\ Trisna Insan Noor ${ }^{2}$ \\ ${ }^{1}$ Program Studi Agribisnis Fakultas Pertanian Universitas Padjadjaran \\ Jl. Raya Bandung-Sumedang Km. 21 \\ ${ }^{2}$ Departemen Sosial Ekonomi Pertanian Fakultas Pertanian Universitas Padjadjaran \\ J1. Raya Bandung-Sumedang Km. 21 \\ *E-mail: nisrina17005@mail.unpad.ac.id \\ (Diterima 01-07-2021; Disetujui 22-07-2021)
}

\begin{abstract}
ABSTRAK
Keberadaan Pandemi Covid-19 di Indonesia memberikan pengaruh bagi Usaha penggilingan padi Kecil (PPK). Dengan adanya bantuan beras yang masif diberikan pada saat awal pandemi guna membantu masyarakat serta untuk menekan angka penyebaran Covid-19, menyebabkan PPK mengeluhkan penurunan pendapatan hingga lebih dari 50\%. Pendekatan berpikir sistem digunakan untuk menggambarkan dinamika yang terjadi, Untuk menggambarkan keterkaitan, digunakan Causal Loop Diagram (CLD). Sementara, untuk mengindentifikasi persoalan serta melihat perilaku, digunakan salah satu teknik PRA (Participatory Rural Appraisal) yaitu menggunakan bagan kecenderungan. pada tahap formulasi model, akan dipergunakan analisis konten. Hasil penelitian menunjukan bahwa Penurunan pendapatan yang dikeluhkan PPK berasal dari kehilangan sejumlah besar penerimaan dari aktivitas produksi beras. Namun, jika dilihat dari sisi pendapatan secara utuh, PPK justru sedang mengalami kenaikan pendapatan yang diakibatkan oleh aktivitas makloon serta sewa lantai jemur karena adanya musim panen dalam rentang waktu tersebut. Keberadaan kedua aktivitas tersebut, membuat PPK bisa bertahan di masa pandemi.
\end{abstract}

Kata kunci: Bantuan Sosial, Beras, Participatory Rural Appraisal, system thinking, Causal Loop Diagram.

\section{ABSTRACT}

The existence of the Covid-19 pandemic in Indonesia has had an impact on the Small Rice Milling Unit (Small RMU). With the massive assistance given at the beginning of the pandemic to help the community and to reduce the spread of Covid-19, causing RMU complain about a decline in income of more than 50\%. Systems thinking approach is used to describe the dynamics. To describe the relationship, a Causal Loop Diagram (CLD) is used. While To identify problems and see behavior, one of PRA (Participatory Rural Appraisal) techniques is used, using a trend chart. A model formulation stage, content analysis is used. The results showed that the decrease in income that RMU complained about loss of a large amount of revenue from rice production activities. However, if viewed from the side of overall income, $R M U$ is actually experiencing an increase in income caused by makloon activities and drying floor rentals due to the harvest season in that time span. The existence of these two activities allows RMU to survive during the pandemic.

Keywords: Social Assistance, Rice, Participatory Rural Appraisal, system thinking, Causal Loop Diagram 


\section{PENDAHULUAN}

Keberadaan Pandemi Covid-19 di Indonesia, turut memberikan pengaruh bagi sistem pangan dan juga daya beli masyarakat (Anugrah, 2020; Saliem 2020). Sebagai sektor usaha yang berkaitan dengan pangan dan juga daya beli masyarakat, usaha penggilingan padi rupanya juga ikut merasakan dampak tersebut.

Penggilingan padi H. Empay merupakan salah satu penggilingan padi kecil (PPK) di Kota Tasikmalaya yang ikut terdampak negatif akibat dari adanya pandemi Covid-19. Hal tersebut dikarenakan ketika masa awal pandemi, pemerintah memberlakukan kebijakan Pembatasan Sosial Berskala Besar (PSBB), dimana pada rentang waktu tersebut berkaitan dengan banyaknya berbagai bantuan dari berbagai pihak termasuk pemerintah yang bersifat tunai maupun natura seperti beras.

Dengan adanya bantuan yang masif diberikan pada saat awal pandemi guna membantu masyarakat serta untuk menekan angka penyebaran Covid-19, menyebabkan PPK mengalami penurunan pendapatan. Sebab, dengan adanya bantuan berupa natura (beras) membuat masyarakat tidak lagi membeli beras. Sejalan dengan Saliem (2020), bahwa kebijakan PSBB yang diterapkan di berbagai wilayah, secara langsung ataupun tidak, memiliki dampak terhadap perubahan permintaan pangan di tingkat konsumen. PPK mengalami penurunan pendapatan dari aktivitas memproduksi beras untuk konsumen tingkat akhir hingga lebih dari $50 \%{ }^{1}$. Tidak hanya terjadi di Tasikmalaya, hal tersebut juga dirasakan oleh usaha penggilingan padi yang ada di Lampung ${ }^{2}$.

Berdasarkan hasil observasi PPK di Kota Tasikmalaya, terungkap kekecewaan serta keluhan yang dirasakan oleh para pengusaha PPK pada kurun waktu tersebut ${ }^{1}$. Pernyataan di atas memberi gambaran bahwa pemberian bantuan beras yang diberlakukan secara masif pada masa awal pandemi Covid-19 merupakan fenomena kompleks yang tanpa disadari memiliki keterkaitan satu sama lain.

PPK mengalami penurunan pendapatan dikarenakan anjloknya permintaan beras, selama kurun waktu kurang lebih dua bulan (Maret-April). Memasuki bulan Mei, stok gabah

\footnotetext{
${ }^{1}$ Berdasarkan hasil observasi awal yang diperoleh dari informan di penggilingan padi pada tanggal $29 / 09 / 2020$

${ }^{2}$ Artikel di Lampost pada tanggal 12/09/2020 jam 16.46 dengan judul 'Usaha Penggilingan Padi di Lampura Kesulitan Jual Beras Petani”. https://www.lampost.co/berita-usahapenggilingan-padi-di-lampura-kesulitanjualberas-petani.html
} 
kembali bisa digiling untuk memproduksi beras untuk konsumen. Sebab, pada kurun waktu tersebut, terdapat momentum zakat fitrah.

Dinamika produksi beras, divisualisasikan menggunakan diagram (Gambar 1) Penulis membagi ke dalam tiga rentang waktu untuk memperlihatkan Behavior Over time. Anjloknya produksi beras merupakan suatu fenomena atau gejala yang pertama kali dirasakan ketika masa awal pandemi. Merujuk kepada paparan di atas, tulisan ini membahas mengenai bagaimana dinamika persoalan yang terjadi pada usaha PPK selama adanya Pandemi Covid-19? Mengapa bisa terjadi penurunan pada saat adanya pandemi? Jika melihat situasi saat ini, pandemi belumlah dikatakan usai, seharusnya PPK masih harus mengalami penurunan produksi beras. Namun, pada kenyataannya (Gambar 1), produksi beras kembali membaik disaat memasuki hari raya sampai dengan saat ini, mengapa hal itu bisa terjadi?

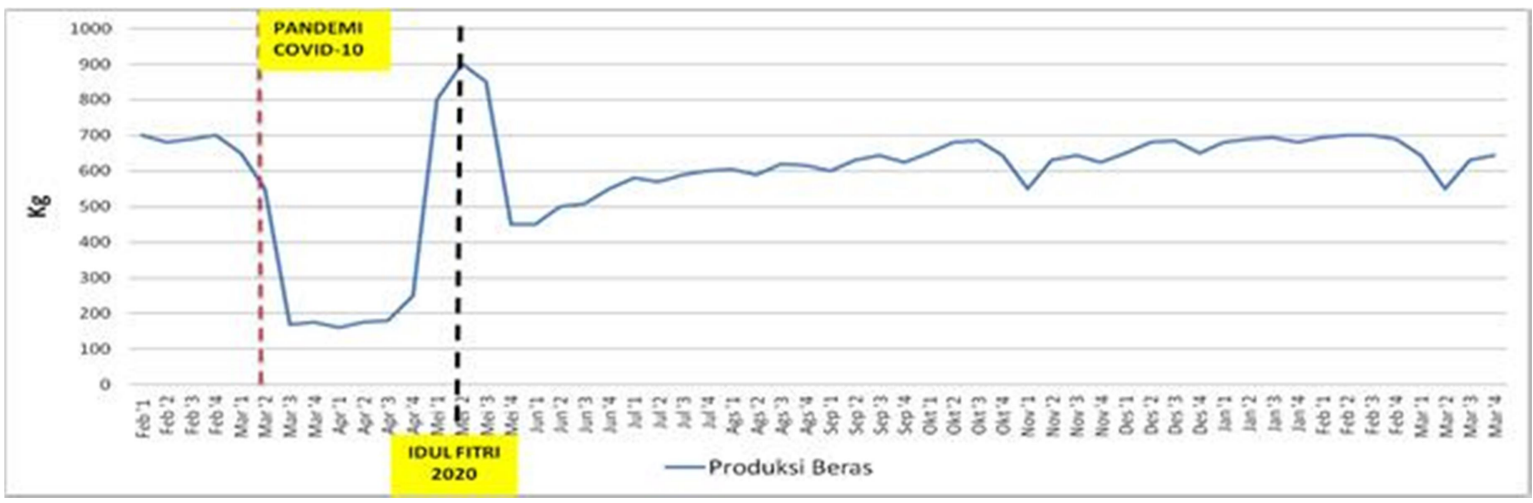

Gambar 1. Dinamika Stok dan Produksi beras di PPK di masa pandemi covid-19 (Data Primer, 2020)

\section{METODE PENELITIAN}

Metode penelitian yang digunakan adalah kualitatif. Hasil dari penelitian kualitatif adalah lebih kepada pemaknaan, memahami keunikan, merancang ulang fenomena, serta menemukan hipotesis (Sugiyono, 2020). Lokasi penelitian berada di Penggilingan Padi H. Empay tepatnya di Kecamatan Purbaratu Kota Tasikmalaya yang dipilih secara sengaja, dimana PPK tersebut mengeluhkan penurunan pendapatan yang disinyalir diakibatkan oleh maraknya bantuan berupa natura yang gencar diberikan kepada rumah tangga pada saat masa awal Pandemi Covid-19. Pendekatan berpikir sistem digunakan untuk menggambarkan dinamika yang terjadi (Richmond, 1993), dimana dengan cara berpikir ini, analisis tidak hanya 
melihat pada satu bagian tertentu, namun akan melihat keseluruhan bagian dari sistem (Heryanto, 2016). Diagram yang dipergunakan dalam system thinking, disebut sebagai Causal Loop Diagram (CLD). Setiap hubungan kausal diberikan polaritas, positif $(+)$ atau negatif (-). Tanda positif mengindikasikan perubahan yang searah, sedangkan tanda negatif mengindikasikan kondisi berlawanan (Richardson, 1986; Sterman, 2000). Setiap variabel yang ada akan selalu terkoneksi dan berhubungan satu sama lain membentuk sebuah lingkaran umpan balik atau feedback loop. Lingkaran umpan balik tersebut bisa berupa pertumbuhan atau reinforcing (R) atau dikenal sebagai feedback loop positif dan bisa juga membentuk feedback loop negatif atau balancing (B) (Sterman, 2000; Forrester, 1961 dalam Bassi, 2020).

Teknik pengumpulan data dalam tulisan ini, mengacu kepada tiga jenis data yang dikemukakan oleh Forrester, yaitu mental database, written database, serta numerical database (Forrester, 1975 dalam Reyes, 2003).

Tahapan analisis data dalam berpikir sistem mengacu kepada four level of thinking yang diawali dengan events, pattern of behavior, systemic structures dan mental models (Morrison, 2001). Digambarkan juga oleh Kirkwood (1998), setiap tahapan yang terjadi dalam cara berpikir ini, bahwa semakin ke arah system structure, artinya memiliki daya ungkit yang semakin tinggi, hal tersebut berarti akan semakin besar kemampuan untuk melakukan perubahan jangka panjang. Analisis dengan cara berpikir ini dimulai dengan mengidentifikasi masalah, kemudian tahap konseptualisasi sistem, dan formulasi model. Untuk membantu melihat perilaku, digunakan salah satu teknik PRA (Participatory Rural Appraisal) yaitu menggunakan bagan kecenderungan (Chambers, 1994). Bagan kecenderungan digunakan untuk memperlihatkan bagaimana perubahan yang terjadi. Pada tahap konseptualisasi sistem dilakukan dengan wawancara mendalam, dan kemudian pada tahap formulasi model dipergunakan analisis konten (Reyes, 2003). Analisis konten yang dilakukan, yaitu dengan system archetype untuk membantu mendiagnosa bagaimana hubungan sebab akibat yang terjadi, atau untuk memahami lebih baik mengenai pertimbangan keputusan (Senge, 2002). 


\section{HASIL DAN PEMBAHASAN}

Profil dan Aktivitas Usaha

Aktivitas usaha yang dilakukan di PPK cukup beragam, yaitu terdiri atas aktivitas maklon (jasa giling serta jasa sewa lantai jemur) dan non maklon (jual beli gabah dan beras). Aktivitas produksi berlangsung setiap hari dengan jam kerja kurang lebih selama enam jam, kecuali pada hari jumat. Setiap minggunya, ratarata berproduksi maksimal $5500 \mathrm{~kg}$ atau kurang lebih $790 \mathrm{~kg}$ per harinya. Sedangkan diketahui bahwa kapasitas produksi mesin dapat mencapai hingga $1500 \mathrm{~kg}$ per jam (PIPA, 2012), hal tersebut berarti PPK bekerja di bawah kapasitas penuh (idle capacity). Sejalan dengan temuan Thahir (2010), dalam Putri (2013), yang menyatakan bahwa sejak tahun 2003 hanya sekitar 40 persen penggilingan padi yang beroperasi dalam kapasitas penuh.

Pelanggan PPK ini merupakan skala rumah tangga yang berlokasi berdekatan dengan PPK. Oleh karena itu, penggilingan padi ini dikategorikan sebagai PPK yang menerapkan konsep rantai pasok pendek. Rantai pasok pendek ini merepresentasikan sebuah jaringan dimana produk akan berpindah langsung dari tangan produsen ke konsumen tingkat akhir dimana peranan dari pihak perantara (middlemen) sangat diminimalisir atau bahkan tidak ada (Todorovic, 2018). Usaha yang menerapkan konsep rantai pasok pendek sangat bergantung dengan keberadaan konsumen tingkat akhir, sehingga ketika ada sedikit gejolak di tingkat konsumen akhir, maka akan langsung dirasakan oleh PPK.

Berdasarkan hasil temuan, produksi beras yang dilakukan diperuntukan bagi rumah tangga langsung dan juga warung terdekat, dengan proporsi masing-masing sebesar 25-30\% dan 70-75\% (Gambar 2). Terdapat perbedaan harga yaitu bagi rumah tangga langsung sebesar Rp10.000, sedangkan bagi konsumen warung sebesar Rp9500 per $\mathrm{kg}$ beras. Untuk dapat memproduksi beras, PPK melakukan pembelian gabah dari petani. Selain beras, terdapat juga dedak serta sekam (by product) yang diperjualbelikan, dengan harga masingmasing sebesar Rp2500 dan Rp300 per kg. Selain memproduksi beras untuk dijual kepada konsumen tingkat akhir, penggilingan padi ini juga menyediakan jasa makloon serta jasa sewa lantai jemur dengan biaya sebesar Rp500 per $\mathrm{kg}$ gabah. 


\section{Dinamika Usaha PPK selama Pandemi Covid-19}

\section{Produksi Beras}

Berdasarkan hasil temuan, produksi beras di PPK didominasi oleh warung (70-75\%). Terlihat pada Gambar 2, bahwa pada saat awal pandemi (MaretApril), penurunan terjadi karena konsumen mereka (warung) cenderung mengalami penurunan dibandingkan dengan konsumen rumah tangga langsung. Terlihat pada Gambar 2, rupanya bantuan beras yang banyak beredar di masyarakat membuat sebagian rumah tangga menghentikan sementara aktivitas pembelian beras ke warung terdekat dikarenakan mereka telah memiliki sejumlah beras.

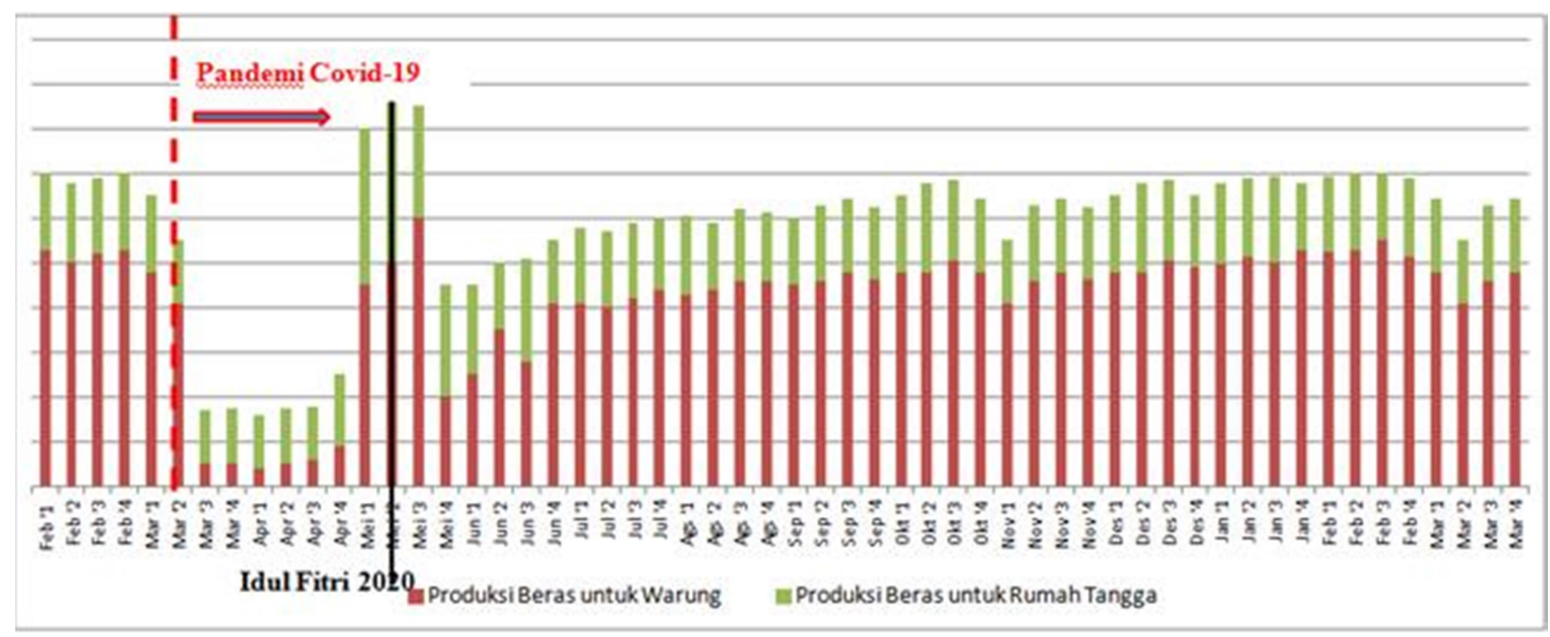

Gambar 2 Dinamika Produksi Beras Selama Pandemi Covid-19 (Data Primer, 2020)

Selain itu, terdapat juga konsumen seorang pedagang berbahan dasar beras yang berhenti membeli beras ke warung dikarenakan konsumen ini menghentikan sementara aktivitas berdagang. Namun, untuk beberapa konsumen rumah tangga yang langsung melakukan pembelian ke PPK (diagram hijau) cenderung stabil dikarenakan jenis konsumen ini adalah mereka yang memiliki daya beli.

Dalam Gambar 2 terlihat bahwa mulai memasuki bulan Mei (menjelang lebaran), aktivitas produksi beras kembali mengalami kenaikan. Jika dilihat berdasarkan jenis konsumen, kenaikan tersebut berasal dari konsumen warung. Berdasarkan hasil temuan, hal tersebut dikarenakan terjadi peningkatan permintaan beras yang diperuntukan untuk membayar zakat fitrah.

Setelah masa idul fitri, perlahan PPK kembali mengalami kenaikan seperti pada masa awal, terutama produksi yang diperuntukan bagi warung. Hal tersebut 
disebabkan oleh banyak hal seperti rumah tangga terdampak yang sudah tidak menerima beras serta perekonomian yang perlahan kembali naik. Salah seorang konsumen yang sebelumnya (sebelum pandemi) tidak pernah melakukan pembelian beras ke PPK, namun pada saat pandemi mendapatkan bantuan tunai yang kemudian dimanfaatkan untuk membuka warung beras, dimana beras tersebut dibeli dari PPK. Sejalan dengan Dermoredjo (2020), bahwa terjadi peningkatan dalam aktivitas perdagangan saat dimulainya masa transisi (Mei-Juni), walaupun belum mencapai situasi normal seperti sebelum ada pandemi (sebelum Maret 2020).

Adanya bantuan dalam bentuk natura (beras) kepada rumah tangga terdampak menyebabkan rumah tangga tidak melakukan pembelian beras ke warung untuk sementara waktu. Karena hal tersebut, maka stok beras yang ada di warung selalu dalam keadaan cukup sehingga menyebabkan warung tidak melakukan pembelian beras ke PPK untuk sementara waktu. Selama kurun waktu dua bulan (Maret-April), PPK kehilangan konsumen yang berasal dari warung. Padahal diketahui bahwa proporsi produksi beras terbesar di PPK, diperuntukan bagi warung (70-75\%).

\section{Jasa Makloon dan Sewa Lantai Jemur}

Selain produksi beras, terdapat juga jasa makloon dan sewa lantai jemur. Dianalisis menggunakan bagan kecenderungan dengan teknik PRA (Gambar 3), terlihat bahwa pada saat masa sulit yang dikeluhkan oleh PPK, di sisi lain terlihat bahwa kedua aktivitas lainnya justru sedang mengalami kenaikan. Hal tersebut dikarenakan keberadaan musim panen di dalam rentang waktu tersebut (Maret-April). Ketika datang musim panen, menyebabkan stok gabah yang ada di petani melimpah, baik yang berupa gabah kering panen (GKP) maupun gabah kering giling (GKG).

Hal tersebut yang mendorong terjadinya peningkatan aktivitas jasa makloon serta sewa lantai jemur di PPK. Terlihat sebuah pola yang cenderung sama atau berulang pada rentang waktu musim panen (Maret-April dan OktoberNovember). 


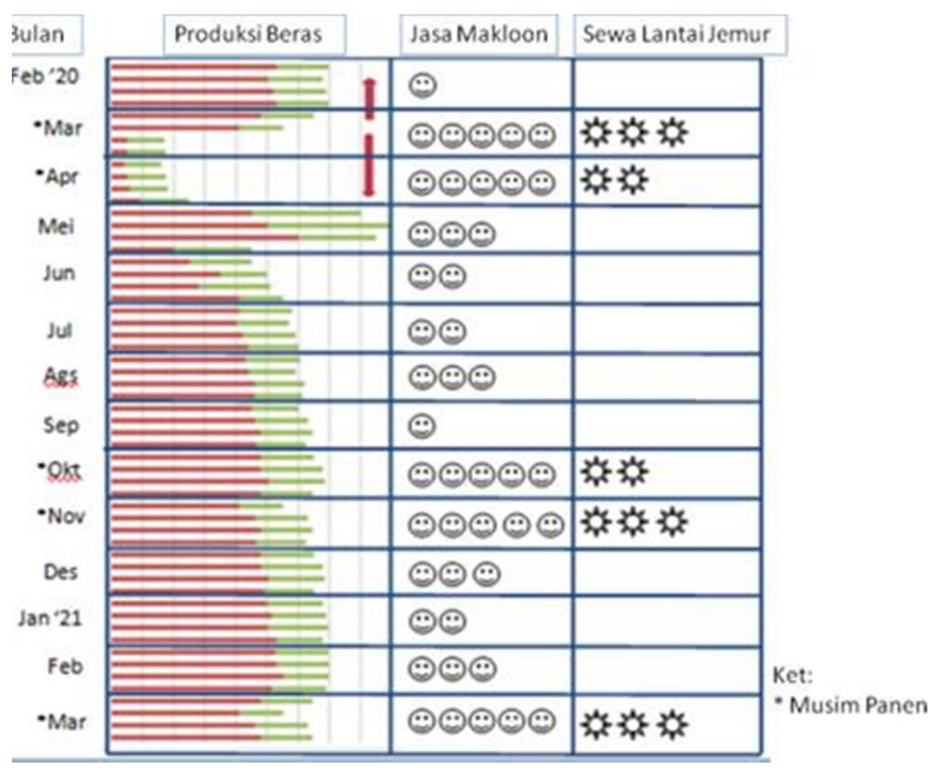

Gambar 3 Pola Perubahan pada setiap aktivitas usaha PPK (Data Primer, 2020)

\section{Pendapatan dan Penerimaan}

Aktivitas yang dilakukan di PPK, yang harus ditanggung terdiri atas biaya tetap dan biaya variabel. dalam tiap tahapannya memiliki biaya

Tabel 1 Proporsi penerimaan dan pendapatan pada setiap aktivitas usaha di PPK

\begin{tabular}{crrrrr}
\hline \multicolumn{3}{c}{$\begin{array}{c}\text { Penerimaan } \\
\text { (Rp/Kg Beras) }\end{array}$} & \multicolumn{1}{c}{ (\%) } & \multicolumn{3}{c}{ Pendapatan } \\
(Rp/Kg Beras) & $(\%)$ \\
\hline Beras & 10000 & 88,85 & Beras & 257,81 & 23,70 \\
Dedak & 396,83 & 3,53 & Dedak & 396,83 & 36,49 \\
Sekam & 95,25 & 0,85 & Sekam & 95,25 & 8,76 \\
Makloon & 262,30 & 2,33 & Makloon & 237,70 & 21,86 \\
Sewa Lantai Jemur & 500,00 & 4,44 & Sewa Lantai Jemur & 100 & 9,19 \\
\hline & & 100 & & 100 \\
\hline
\end{tabular}

Sumber: data primer, 2020

Diketahui bahwa proporsi biaya terbesar yaitu berasal dari biaya bahan baku yaitu kurang lebih mencapai $81,47 \%$. Setelah sebelumnya diketahui bahwa terdapat dua ativitas lainnya yang ternyata cenderung meningkat pada saat terjadi penurunan produksi beras, perlu dilakukan analisis perkiraan pendapatan serta penerimaan pada tiap-tiap aktivitas yang ada. Hal tersebut bertujuan untuk melihat secara lebih utuh, apakah PPK benar-benar mengalami kerugian.

Terlihat pada Tabel 1, bahwa proporsi penerimaan dari beras merupakan yang terbesar, yaitu sebesar 88,85\%. Akan tetapi, ditemukan hal berbeda pada proporsi pendapatan. Beras sebagai penerimaan terbesar belum tentu menjadi sumber pendapatan utama bagi PPK dimana, proporsi pendapatan terbesar bukan berasal dari beras, namun 
berasal dari dedak sebagai by product diikuti oleh jasa makloon $(21,86 \%)$. Hal ini juga sejalan dengan temuan putri (2013) yang membuktikan bahwa keberadaan usaha penggilingan padi sangat bergantung pada by product (sekam dan dedak) bukan pada beras sebagai output utama, banyak penggilingan padi yang tidak menyadari kondisi tersebut, dan menyebabkan hanya fokus pada pengembangan beras sebagai aktivitas utama.

Rupanya, penurunan pendapatan yang dikeluhkan PPK dikarenakan mereka kehilangan sejumlah besar penerimaan dari aktivitas produksi beras. Artinya, sumber penerimaan utama dan terbesar milik mereka berasal dari beras, dan ketika rumah tangga berhenti untuk membeli beras, PPK telah kehilangan sumber penerimaan utama. Namun, kedua aktivitas lainnya (jasa maklon dan sewa lantai jemur) perlu juga dilihat, mengingat adanya keberadaan musim panen dalam rentang waktu tersebut (Gambar 3).

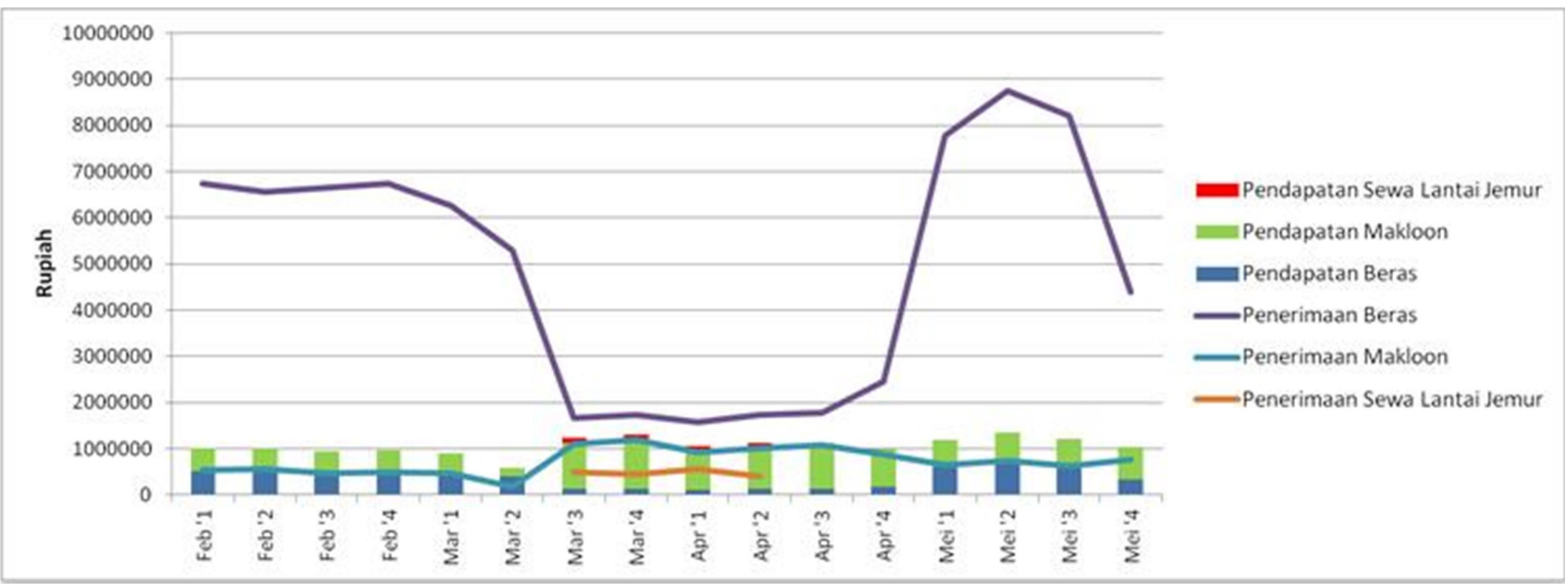

Gambar 4 Penerimaan dan Pendapatan mingguan PPK Bulan Februari 2020-Mei 2020 (Data Primer, 2020)

Terlihat pada Gambar 4 bahwa pada saat masa awal pandemi, PPK memang mengalami penurunan pendapatan dari beras. Namun, jika dilihat dari sisi pendapatan secara utuh, PPK justru sedang mengalami kenaikan pendapatan yang diakibatkan oleh aktivitas makloon serta sewa lantai jemur. Keberadaan kedua aktivitas tersebut, membuat PPK bisa bertahan selama masa awal pandemi. Hal tersebut sejalan dengan temuan Sobirin (2015), bahwa untuk dapat bertahan, usaha penggilingan padi kecil tidak bisa hanya mengandalkan pada satu jenis aktivitas, mereka diharuskan untuk memiliki usaha 
lain agar bisa tetap bertahan. Dalam konsep berpikir sistem, perilaku suatu fenomena dimunculkan oleh strukturnya, struktur tersebut yang bertanggung jawab terhadap suatu perilaku (Sterman, 2000; Heryanto, 2016).

\section{Struktur Sistem Penjualan dan Konsumen Beras PPK di masa pandemi}

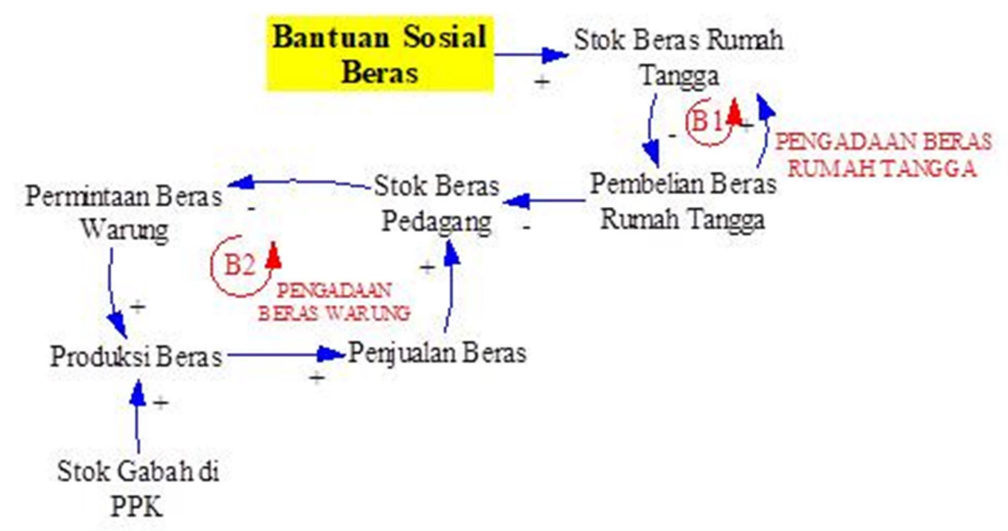

Gambar 5. struktur Causal Loop Diagram dampak bantuan beras terhadap konsumen PPK di masa pandemi (Data Primer, 2020)

Pada masa awal pandemi Covid-19, adanya kebijakan PSBB telah menghentikan kegiatan ekonomi masyarakat serta secara tidak langsung berdampak pada berkurangnya volume produksi, penjualan (supply side), dan pembelian oleh konsumen (demand side)
(Aziz, 2020). Adanya bantuan beras yang secara massif diberikan pda masa awal pandemi saat berlangsungnya kebijakan PSBB menjadi pendorong awal terjadinya perubahan dari sisi pengadaan beras rumah tangga (B1).

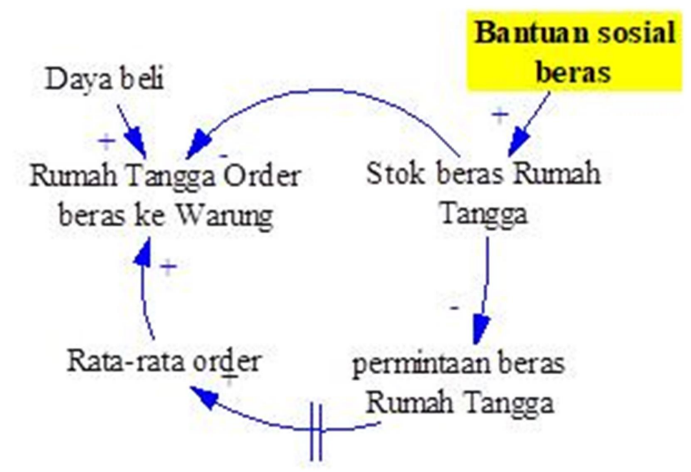

Gambar 6. Struktur Causal Loop Diagram keputusan konsumen Rumah Tangga

Hal tersebut berpengaruh terhadap keputusan rumah tangga untuk mengentikan sementara pembelian beras ke warung dikarenakan stok beras di 
rumah tangganya masih tersedia. warung. Sejalan dengan Saliem (2020), Beberapa rumah tangga yang tidak bahwa kebijakan PSBB di berbagai mendapatkan bansos, masih memiliki daya beli sehingga mampu melakukan pembelian ke warung. Kondisi tersebut wilayah, secara langsung maupun tidak lansung berdampak pada perubahan permintaan pangan di tingkat konsumen.

rupanya berpengaruh cukup besar bagi PPK sebagai produsen beras bagi

\section{Struktur Sistem Perputaran Usaha PPK}

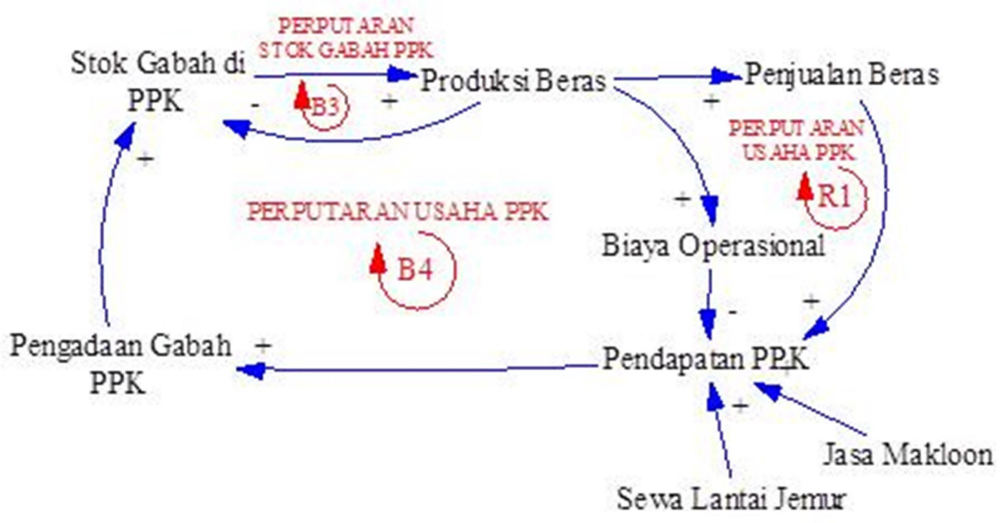

Gambar 7. Struktur Causal Loop Diagram Perputaran usaha PPK (Data Primer, 2020)

Seperti telah diketahui sebelumnya, pendapatan PPK tidak hanya berasal dari aktivitas jual beli beras. Pendapatan tersebut mempengaruhi pengadaan gabah di PPK. Semakin besar pendapatan yang diperoleh, maka akan semakin besar pula kemampuan pengadaan gabah di PPK, yang akan berimbas pada stok gabah di PPL. Biaya operasional bukan merupakan pertumbuhan, namun akan menjadi penyeimbang yang suatu waktu bisa berkebalikan (B4) sehingga menjadi unsur yang tidak kalah penting untuk diperhatikan oleh pemilik PPK, seperti persoalan efisiensi dan lainnya. PPK akan menjadi usaha yang stagnan serta sulit berkembang karena sisi internal, sehingga PPK lebih banyak yang bertahan dengan cara mencari aktivitas usaha lainnya, dibandingkan tumbuh berkembang (Sobirin, 2016). PPK juga perlu terus memperhatikan keseimbangan stok gabah sebagai bahan baku (B3). 


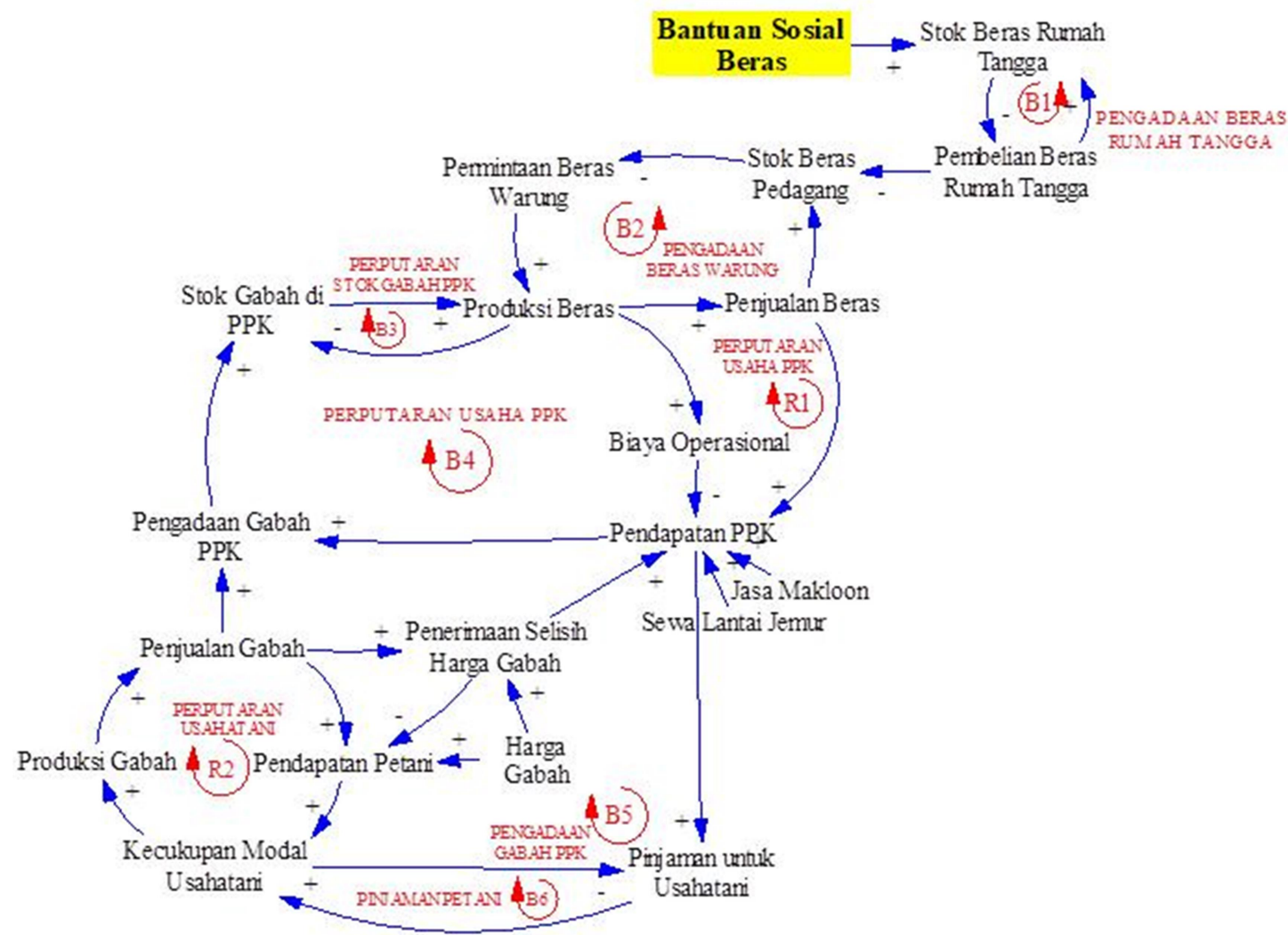

Gambar 8 Struktur Causal Loop Diagram Sistem usaha PPK di masa pandemi (Data Primer, 2020)

\section{KESIMPULAN DAN SARAN}

\section{Kesimpulan}

1. Adanya bantuan beras yang masif diberikan pada masa awal pandemi saat berlangsungnya PSBB, menjadi pendorong terjadinya perubahan dari sisi pengadaan beras rumah tangga (B1). Hal tersebut berpengaruh terhadap keputusan rumah tangga untuk mengentikan sementara pembelian beras ke warung karena stok beras di rumah tangga masih tersedia.

2. Beras sebagai penerimaan terbesar belum tentu menjadi sumber pendapatan utama bagi PPK.
Penurunan pendapatan dari beras masih bisa diatasi oleh aktivitas usaha lain diantaranya jasa makloon serta sewa lantai jemur.

3. Jasa Makloon serta sewa lantai jemur meningkat saat musim panen raya (Maret-April dan OktoberNovember). Kedua aktivitas ini, membuat PPK bisa bertahan di masa pandemi.

\section{Saran}

1. Pemberian bantuan berupa natura disarankan agar dapat dikombinasikan dengan bantuan yang bersifat tunai agar perputaran ekonomi di daerah tetap berjalan. 
2. Jika pemerintah kembali akan memberikan bantuan berupa natura, sebaiknya pengadaan barang dilakukan dengan cara bekerja sama dengan retail lokal atau setempat.

\section{DAFTAR PUSTAKA}

Anugrah, I. S., Saputra, Y. H., \& Sayaka, B. (2020) DAMPAK PANDEMI COVID-19 PADA DINAMIKA RANTAI PASOK PANGAN POKOK. Draft makalah Buku Bunga Rampai Covid-19 Bogor (ID): Pusat Sosial Ekonomi dan Kebijakan Pertanian.

Azis, M., Dermoredjo, S. K., \& Susilowati, G. (2020) Dampak Pandemi Covid-19 Terhadap Investasi Sektor Pertanian.

Bassi, A. M., Bianchi, M., Guzzetti, M.M., Pallaske, M.G., \& Tapia, C. (2020). Improving the understanding of Circular Economy potential at territorial level using Systems Thinking. Sustainable Production and Consumption, Vol.2, p. 128-140.

BPS. (2012). Pendataan Industri Penggilingan Padi (PIPA). Katalog BPS:6106001. Oktober2012.

Chambers. R. (1994). The origins and Practice of Participatory Rural Appraisal. World Development, 22(7), 953-969.

Dermoredjo, S. K., Saputra, Y.H., \& Azahari, D.H. (2020). Dampak Pandemi Covid-19 Terhadap Perdagangan Dalam Negeri Komoditas Pertanian.

Heryanto, M.A. dkk. (2016). Model Perilaku Petani dalam Adopsi Sistem Usahatani Padi Organik: Paradoks Sosial-EkonomiLingkungan. Jurnal Sosiohumaniora, 18(2), 159-165.
Kirkwood, C. W. (1998). System dynamics methods: A quick introduction. College of Business, Arizona State University, 126.

Luna-Reyes, L. F., \& Andersen, D. L. (2003). Collecting and analyzing qualitative data for system dynamics: methods and models. System Dynamics Review: The Journal of the System Dynamics Society, 19(4), 271-296.

Morrison, Terrence. 2001. Actionable Learning: A Handbook for Capacity Building Through Case Based Learning. Japan: Asian Development Bank Institute

Putri, T. A., Kusnadi, N., \& Rachmina, D. (2013). Kinerja Usaha Penggilingan Padi, Studi Kasus Pada Tiga Usaha Penggilingan Padi Di Cianjur, Jawa Barat. Jurnal Agribisnis Indonesia, 1(2), 143-154.

Richardson, G. P. (1986). Problems with causal-loop diagrams. System dynamics review, 2(2), 158170.

Richmond, B. (1993). Systems Thinking: Critical Thinking Skills for the 1990s and Beyond. System Dynamics Review, 9(2): 113-133.

Saliem, H. P., Agustian, A., \& Perdana, R. P. (2020). Dinamika harga, permintaan, dan upaya pemenuhan pangan pokok pada era pandemi Covid-19. Draft makalah Buku Bunga Rampai Covid-19. Bogor (ID): Pusat Sosial Ekonomi dan Kebijakan Pertanian.

Senge, P. (2002). Buku Pegangan Disiplin Kelima, Strategi dan Alatalat untuk Membangun Organisasi Pembelajaran. The Fifth Discipline Fieldbook. Alih Bahasa Hari Suminto. Batam: Interaksara. 
Sterman, John D. (2000). Business

Dynamics: System Thinking and Modeling for a Complex

World. United State of America (USA): McGraw-Hill Higher Educatiion

Sobirin, A., \& Rosid, A. (2016). Entrepreneurial orientation of family firm within maturity industry: A Multi-Case Study in Rice Milling Industry in Indonesia. Procedia-Social and Behavioral Sciences, 219, 710716.
Sugiyono. (2020). Metode Penelitian Kualitatif. Bandung. Alfabeta.

Todorovic, V., Maslaric, M., Bojic, S., Jokic, M., Mircetic, D., \& Nikolicic, S. (2018). Solutions for more sustainable distribution in the short food supply chains. Sustainability, 10(10), 3481. 